\title{
Representaciones de la obesidad en la cuentística de Franz Galich y de Carlos Velázquez ${ }^{1}$
}

\section{(Representations of Obesity in Short Stories by Franz Galich and Carlos Velázquez)}

Carlos Andrés González Hernández²

Ministerio de Educación Pública

\section{RESUMEN}

Se describe y analiza cómo se perciben los cuerpos obesos, en el ambito social, en la literatura contemporánea en dos países latinoamericanos. Se examinan las diversas apreciaciones discursivas sobre la obesidad que exponen los personajes en las tramas textuales. Para esta aproximación interpretativa, se acude a fundamentos conceptuales sociológicos y narratológicos.

\begin{abstract}
A description and an analysis are provided of how obese bodies are perceived at a social level in contemporary literature in two Latin American countries. Different discursive views of obesity that the characters display in the textual plots are examined. For this interpretative approach, sociological and narratological concepts are applied.
\end{abstract}

Palabras clave: cuento hispanoamericano, obesidad, discriminación corporal, sexualidad

Keywords: Hispanic American short story, obesity, corporal discrimination, sexuality

1 Recibido: 11 de marzo de 2019; aceptado: 4 de junio de 2019.

2 Departamento de Bibliotecas Escolares y Centro de Recursos para el Aprendizaje. Ministerio de Educación Pública. Correo electrónico: carlos.gonzalez.hernandez@mep.go.cr 


\section{Introducción}

En diversas etapas de la historia, la condición de la obesidad ha tenido una connotación excluyente que provoca baja autoestima en quien la tiene. Además, las personas se pueden convertir en potenciales víctimas del hostigamiento público; o bien, fáciles de manipular por quien busque particular interés.

En la literatura latinoamericana contemporánea también se percibe infinidad de estereotipos que degradan a los gordos en los diversos ámbitos sociales en los que se desenvuelven (el laboral, las relaciones de pareja, la familia y el convivio con amistades). En este estudio se analiza lo monstruoso y su vinculación con los comportamientos de los personajes en los cuentos seleccionados. En primer lugar, se define la voz obesidad para comprender su alcance dentro del ámbito social:

Es una enfermedad multifactorial, crónica y recidivante, fruto de la interacción entre genotipo y ambiente, caracterizada por el almacenamiento excesivo de grasa en el tejido adiposo, que pone en peligro la salud y la expectativa de vida de la persona que la padece. La asociación de la obesidad con el nivel socioeconómico, y otros factores como el género, edad y etnicidad es compleja y dinámica»³.

A pesar de esta tesis médica, a la persona obesa socialmente no siempre se la califica como enferma; más bien, se la insulta o se la excluye de los grupos a los que frecuenta.

Desde el punto de vista histórico, los primeros vestigios que se tienen de una percepción física de los cuerpos obesos en la cultura humana proceden de unas pequeñas esculturas llamadas Venus; la más conocida es la de Willerdorf, tallada en piedra caliza, de unos

3 Domingo Bartolomé et al., «La estigmatización social de la obesidad», Cuadernos de Bioética 25, 2 (2014): 273-284. 
25.000 años A. C., hoy día en el Museo de Historia Natural de Viena ${ }^{4}$, según lo apunta Francisco Puerto Sarmiento en «La obesidad: una visita a la Historia». En la Edad Media, la gordura no se estigmatiza, ni siquiera en sus casos más extremos. Era un símbolo más de poder social. Indica Puerto Sarmiento que se mantuvo durante el siglo XVII en Europa como un símbolo de poder, principalmente entre banqueros, negociantes y hombres de finanzas: «Por eso, prácticamente hasta el Barroco e incluso durante el mismo para algunos artistas, lo gordo era bello, reflejo del poder y fuente de erotismo» ${ }^{5}$. Subraya Puerto Sarmiento que, desde finales del siglo XIX: «la obesidad extrema se había convertido en monstruosa e incluso se exhibía como atracción en barracas de ferias $»^{6}$. Sin embargo, es en la segunda mitad del siglo xx que se consolida el discurso de la obesidad como sinónimo de rechazo social, discriminación, repudio y menosprecio al individuo cuya corporalidad es voluminosa en contraste con lo normado: «El obeso extremo pasa a ser un caso clínico y se establece como precepto último de belleza» ${ }^{7}$.

En el ámbito laboral, a los obesos se les dificulta encontrar trabajo. No cabe duda de que se incurre en discriminación si a un obeso se le niega un empleo ante su apariencia, a pesar de estar debidamente calificado. A la persona con gordura se la tipifica como perezosa, descuidada y desaliñada, que, además, sufre de una serie de padecimientos relacionados con su peso y es víctima de un constante bullying en su quehacer cotidiano con apodos, representaciones caricaturescas o ataques injuriosos en las redes distintas sociales. Por tanto, la forma de abordar el tema de la obesidad y sus consecuencias no debe provenir del ámbito clínico, ya que hay un componente antropológico y sociológico que debe analizarse de forma simultánea, y que está plasmado en la literatura latinoamericana contemporánea.

4 Fernando Puerto et al., «La obesidad: una visita a la historia», Anales de la Real Academia de Farmacia, 82 (2016): 27-43.

5 Puerto, 370.

6 Puerto, 381.

7 Puerto, 379. 
Como lo señala María Alejandra Energeci, en «Gordura, discriminación y clasismo: Un estudio en jóvenes de Santiago de Chile», existe una marcada segregación social para los cuerpos gordos:

Para el caso de la obesidad, se invisibiliza que los juicios sobre el tamaño del cuerpo se realizan en contextos que ya poseen lógicas de discriminación por género, edad y/o nivel socioeconómico. En otras palabras, estos estudios tienden a omitir que existe una estratificación social de los cuerpos o que en los cuerpos se encarna dicha estratificación ${ }^{8}$

Así, el sujeto obeso carga con una imagen peyorativa que le dificulta, en distintos ámbitos sociales, la aceptación y el desarrollo para sobrellevar sus tareas cotidianas, en que el culto a la delgadez y al cuerpo estilizado es la norma que rige el canon estético deseable para cualquiera. Cabe señalar la dificultad que sufre una persona obesa para entablar una relación afectiva. En general, se avergüenzan de su voluminosa corporeidad, que los aleja de la posibilidad de entablar una relación seria con algún individuo. Incluso, esconden su cuerpo de la mirada acusadora del colectivo, que los señala con asociaciones zoomórficas para denigrar su aspecto físico. Al estar tan valorado el cuerpo delgado a nivel social, queda por fuera la persona con superávit de grasa, descalificándosele y desdeñando su identidad; además, señala Baltasar Fernández que:

En este caso, el discurso preponderante se elabora en términos de salud y enfermedad. Cercanas a cierta imagen de marginalidad social, las personas obesas quedan retratadas como voraces, enfermas del exceso de apetito, incapaces de controlarse y de realizar sencillos esfuerzos sin ayuda externa, síntoma o preludio de múltiples patologías que comprometen a todos los sistemas vitales, anormales en su cuerpo, su tamaño y su entorno social, raras, peligrosas para los suyos por influir en hábitos alimenticios de riesgo, perezosas, caras

8 Alejandra Energeci et al., «Gordura, discriminación y clasismo: Un estudio en jóvenes en Chile», Revista Artigos 29 (2017): 1-10. DOI: https://doi.org/10.1590/1807-0310/2017v29164178. 
para el sistema sanitario e inútiles para el contexto laboral, entre otras lindezas supuestamente avaladas por la comunidad científica ${ }^{9}$

Por último, según lo indica Domingo Bartolomé, «los efectos indeseables derivados de la obesidad afectan más a las mujeres que a los hombres, producto de una satanización de la obesidad mediatizada por el culto al cuerpo» ${ }^{10}$. Para nuestro análisis de los cuentos, se abordan las relaciones de poder que ejercen los personajes dentro de la ficción, el narrador y sus modos de focalización y su vinculación con el tema de lo monstruoso; además, de cuáles recursos retóricos emplean los escritores para construir las representaciones de los cuerpos obesos en la trama textual.

\section{Los cuerpos obesos percibidos como seres grotescos y monstruosos}

En el relato de Franz Galich «La Turquita y la Comecuanday» ${ }^{11}$ se presenta la historia de dos mujeres de clase baja en que habitan un barrio pobre de un país centroamericano, rememorando una amena experiencia vivida cuando fueron competidoras para cuál era la campeona para comer más. El narrador, representado por el personaje de la Comecuanduay, nos ubica espacialmente en una fiesta popular de esta contienda gastronómica. El duelo empieza evocando una imagen pantagruélica e hiperbolizada de la enorme cantidad de alimentos que van a consumir estas gladiadoras durante su desafío:

Lo primero que hiciste fue pedir que en un balde te echaran diez cervezas bien frías, las cuales te tomaste en menos de lo que canta un gallo. Para acompañarlas te sirvieron unos chicharroncitos, y te pasaron unos que parecían sombreros mexicanos, de esos que les dicen charros. Yo, como a vos te consta, no soy ninguna ofrecida,

9 Baltasar Fernández et al., «El discurso popular sobre la obesidad. Análisis de contenido de una discusión virtual», Revista de Ciencias Sociales 52 (2012): 1-40.

10 Bartolomé, 282.

11 Franz Galich, Perrozompopo y otros cuentos latinoamericanos (Managua: Anamá Ediciones, 2017) 45-50. 
pero tampoco me gusta que me vulgareen, ni que me hagan de menso. Entonces pedí que me trajeran una cajilla de cervezas, sólo que, como a mí no me gustan los chicharrones secos, pedí que me mandaran tres libras de frito de yuca, y para no quedarme atrás, me lo tomé en un santiamén ${ }^{12}$.

Conviene tener en cuenta lo que indica Mijail Bajtín en La cultura popular en la Edad Media y en el Renacimiento: El contexto de Francois Rabelais, en torno a la fuerte relación que existe entre el banquete y el cuerpo grotesco; en este caso lo representa la enorme y monstruosa gordura que ofrece de ambos personajes: «Las imágenes del banquete están estrechamente ligadas a las del cuerpo grotesco [...] El comer y el beber son las manifestaciones más importantes de la vida del cuerpo grotesco. Los rasgos particulares de este cuerpo son el ser abierto, estar inacabado y en interacción con el mundo» ${ }^{13}$. Se hiperbolizan las dimensiones corporales a un punto grotesco para lograr la ingesta de comida. Así, existe una relación entre el cuerpo y lo monstruoso. Lo señalado lo estudia Rafael Ángel Herra en su ensayo sobre la monstruosidad: «Lo monstruoso encarna vagos reflejos de independencia. Las ambigüedades de la rebelión total toman forma y se deforman en cada bestia que cruza el mundo. Lo monstruoso es lo diferente, el horror a las diferencias $»{ }^{14}$. Tanto la Turquita como la Comecuanduay irrumpen en la vida cotidiana del lugar donde habitan, con el fin de competir por el título a la que más devora alimentos.

Sin embargo, esa monstruosidad desenmascara un enorme problema social: son mujeres que buscan saciar su hambre, lo cual da ejemplos de una sociedad latinoamericana tercermundista sumergida en la pobreza extrema, producto de la mala administración del poder político. De ahí, la relevancia del significado del término monstruo,

12 Galich, 45-46.

13 Mijail Bajtín, La cultura popular en la Edad Media y en el Renacimiento: El contexto de Francois Rabelais (Madrid: Alianza Editorial, 2003) 227.

14 Rafael Ángel Herra, Lo monstruoso y lo bello (San José: Editorial Universidad Costa Rica, 1988) 12-13. 
vinculado con la denuncia social subsumida en las figuras de los dos personajes del cuento: «Significa mostrar, designar, indicar; en otras palabras, monstruo es signo (cierta realidad que está por otra y ciertos códigos que rigen la función) $\rangle^{15}$. Ello se percibe en lo desproporcionado de las mujeres, y que el narrador expone aludiendo a las enormes carencias económicas de los países tercermundistas: «A todo esto, el turcazo de gente que estaba en el gimnasio, ya se habían enterado de tu llegada: una descomunal hembrita, que fácilmente llegabas a las ochocientas libras, y yo, con mi cuerpecito que parecía Miss Tercer Mundo. ¡Imagínate!: puro esqueleto de pescado. Así que todo el mundo se fue acercando por donde nosotras» ${ }^{16}$.

Se entrevé que la corporeidad voluminosa fortalece el estereotipo negativo que se les adjudica a los individuos que la padecen. Sin embargo, ambas mujeres, al competir en una fiesta, son aceptadas por el conglomerado que se aglutinó a observarlas. Ellas son motivo de admiración y atraen al público que las vitorea durante el festín: «De pronto, allá arriba, en las gradas, un loco gritó a galillo partido: “¡Mil pesos por la Turquita!” E inmediatamente alguien le gritó: “iiMe agarrás a besos!!" Y así sucesivamente. Pero otro, tal vez con un sentido más patriótico gritó: “¡Dos mil a la Comecuanduay!” y otro: “¡Pago y quinientos más a la Turquita!” "¡Tres a la Comecuanday”! Y fue así como se formaron las barras: " $i$ Turquita, Turquita, Turquita". "Comecuando-hay", Comecuanduay", "Comecuanduay» ${ }^{17}$. Se nota que las mujeres provocan excitación y algarabía con ese modo de comer. Esto ratifica lo que apunta Herra en relación con el simbolismo de lo monstruoso y su relación con el cuerpo:

El monstruo es el resultado de una tragedia sin desenlace, en la cual la anagnórisis solo se verifica a medias. Lo temible de la realidad se enmascara con rostros excepcionales. Aquellos hechos a todas luces inmanejables por el ciudadano común, la pérdida de democracia, la

15 Herra, 31.

16 Galich, 46.

17 Galich, 47. 
concentración insoportable del poder, el exterminio de toda clase de vida, la violencia universal, la inmundicia lanzada contra los demás porque no son como yo quiero que sean, los grandes abusos financieros, estos hechos inmanejables provocan una especie de shock continuo, borroso, maloliente, un asedio contra la conciencia ingenua de la cotidianidad ${ }^{18}$.

Pese a que es una amena divirsión para el colectivo presenciar a dos mujeres obesas compitiendo por quién come más, importante son las desigualdades sociales que ellas representan. Por un lado está la necesidad de buscar a toda costa cómo satisfacer las necesidades fisiológicas básicas como la alimentación diaria; por otro, lo monstruoso está representado por el mal manejo de la riqueza que han tenido los diferentes gobiernos durante mucho tiempo para con los colectivos, lo cual fortalece ese ambiente de pobreza extrema que reina en la región centroamericana, y que se ha mantenido desde principios del siglo XX.

En otro orden de cosas, hay cierto grado de atractivo erótico en los cuerpos de esas mujeres; en el caso de la Turquita: «Hiciste un ademán con tus manazas y al llegar, el bueno-para-nada, Malagana, que dicen que le gustaste para hacerte suya, como que no se diera cuenta que al abrazarte hubiera quedado como lagartija en ceiba» ${ }^{19}$; esto fortalece la importancia de la sexualidad como factor en el cuerpo grotesco. Así, en la trama textual se proyecta peyorativamente la idea de que el cuerpo obeso mata a la persona, por el simple hecho de compartir un momento de intimidad sexual. Estas particularidades descomunales del cuerpo mórbido las plantea Bajtín como propias, del realismo grotesco: «La exageración, el hiperbolismo, la profusión, el exceso son como es sabido, los signos característicos más marcados del estilo grotesco ${ }^{20}$.

Herra estudia la imbricación entre lo monstruoso y lo carnavalesco como binomio que integra al cuerpo obeso: «El monstruo es

18 Herra, 15.

19 Galich, 47.

20 Bajtín, 249. 
metonímico: es una parte sígnica de la realidad por medio de la cual se representa el todo. Esta función metonímica hace posible resistir lo amenazante, la angustia de realidades pavorosas: por ser la parte fea, a veces risible y carnavalesca, el monstruo carga con todo lo horrendo del mundo cotidiano» ${ }^{21}$. A partir de esa imagen caricaturesca que exhiben la Turquita y la Comecuanduay, se reafirma una problemática asociada a la marginalidad y al abandono que viven muchos en Centroamérica. El cuento empieza y finaliza con la misma frase, parodiando las calamidades que deben padecer los habitantes de un barrio azotado por la escasez económica para subsistir diariamente: «El hambre es mala consejera....» ${ }^{22}$.

Por otro lado, el narrador, que ofrece una focalización interna fija, la cual, como lo señala Luz Aurora Pimentel en El relato en perspectiva: Estudio de teoría narrativa, «coincide con una mente figural; es decir, el narrador restringe su libertad con objeto de seleccionar únicamente la información narrativa que dejan entrever las limitaciones cognoscitivas perceptuales y espaciotemporales de esa mente figural $\rangle^{23}$, acentúa ese panorama de extremosidad que determina al cuerpo grotesco, que se refleja directamente en la obesidad de las mujeres. A continuación, se observa esa glotonería exagerada nuevamente, cuando la Turquita y la Comecuanduay vuelven a pedir algo para comer, que solamente sus cuerpos podrían soportar:

Entonces, pediste un novillo asado, también entero, con ensalada de repollo, que consistió en veinte repollos a medio encurtir con un frasco de cinco galones de chilero, cincuenta tortillas, diez cajillas de cervezas y una caja de guaro. Yo, niña, como ya me conocés, pedí una vaca asada, revuelta con un cerdo frito bien revolcado con achiote, cinco cajas de tomate de ensalada, diez libras de chile congo y un saco de lechuga, todo eso regado con su respectivo vinagre

21 Herra, 16.

22 Galich, 45.

23 Luz Aurola Pimentel, El relato en perspectiva: Estudio de teoría narrativa (Ciudad de México: Siglo XXI Editores, 1998) 99. 
y aceite de oliva. Luego pedí seis sifones de cervezas, cuatro cajas de ron, y dos de güisconsin y una pichinga de veinticinco litros de leche, con quinientos picos con su respectiva jalea, crema y queso, porque así quedan divinos ${ }^{24}$.

Estos espectáculos de ingestión brutal de alimentos reafirman el estigma de que las personas gordas son insaciables y muy descuidadas con su salud, por cuanto no prevén los problemas que les traerá en el futuro. Así, reitera Bajtín, el rasgo particular y esencial de lo grotesco es «la exageración caricaturesca de un elemento negativo» ${ }^{25}$. Esto se advierte en la trama textual, con el uso de metáforas y símiles que fortalecen el aspecto deforme y grotesco de los cuerpos obesos de ambas mujeres: «Te pusiste de pie y levantaste tus enormes brazos de ceiba humana, temible, la Mamulona, que más bien así debieron decirte, y no Turquita. De pronto, empecé a ensancharme, poco a poco: primero me fui poniendo como salchichón, después como pelota de básquetbol y, finalmente, como Zeppelín» ${ }^{26}$. Para Bajtín, la figura del gigante es propia de la corporeidad grotesca: «El gigante es por definición la imagen grotesca del cuerpo» ${ }^{27}$. Esto se capta en las dimensiones colosales de la Turquita y la Comecuanduay.

Además, lo carnavalesco se afianza en lo monstruoso para acercarse a la estrategia de mediación satírica, según lo indica Herra: «El carnaval también se vale del monstruo como vehículo de la parodia. Ambos fenómenos son un gran juego distanciador: el monstruo es bello, tan bello como las caricaturas, como la parodia» ${ }^{28}$. En el cuento de Galich el efecto monstruoso de devorar insaciablemente muestra un tono burlesco ante la realidad circundante de las sociedades centroamericanas, que carecen de recursos económicos para pagar esa cantidad exorbitante de alimentos, cuando más bien siempre están

24 Galich, 49.

25 Bajtín, 251.

26 Galich, 47-49.

27 Bajtín, 280.

28 Herra, 35. 
riesgo de ni siquiera conseguir lo necesario para sufragar la canasta básica que consumen a diariamente.

Otro aspecto que Bajtín indica es el relacionado con los fluidos corporales, que se manifiestan de una manera estrambótica en estos dos personajes del cuento. Señala Bajtín que «esta es la razón por la cual los acontecimientos principales que afectan el cuerpo grotesco, los actos del drama corporal, el comer, el beber, las necesidades naturales (y otras excreciones: transpiración, humor nasal, materia fecal y la orina) ${ }^{29}$. En el cuento se observa esa alusión desmedida que se refiere a la producción fisiológica de la orina y del excremento, que solamente un cuerpo obeso puede elaborar. A nivel social, hay una fuerte ironía contra el poder estatal, por cuanto no brinda el debido acompañamiento al ciudadano pobre para que surja a nivel personal. Esto se visualiza irónicamente en el nombre del personaje «la Comecuanduay», que remite a que su condición de pobreza es extrema y solamente consigue saciar su apetito únicamente cuando la invitan, como sucedió en la competencia de comelonas que organizaron en su comunidad. En las citas siguientes, se presentan tales referencias a estos dos fluidos corporales, que también provocan mofa hacia los grupos de poder y las normas de comportamiento social idóneo:

Fue entonces que me entraron las ganas de miar. Yo me fui al servicio, y para qué te cuento, el chorro que eché, con decirte que se rebalsó la taza y se salió por los corredores. [...] mientras, vos, Turquita, desaparecías en el aire, defecando y defecando, inundando todo el gimnasio de ñaña. Me somaté suavemente en el estómago con el fin de soltar un buen pedo, cosa que no se hizo esperar, sólo que como soy flaca, fue chifladito. Lo único que duró casi diez minutos, pues ya tenía bastante presión acumulada, bien comprimida. Entre la multitud alguien gritó: «¡Compro esa trompeta con todo y estuche! $\gg^{30}$

29 Bajtín 260.

30 Galich, 48-51. 
La risa alegre entre los dos personajes también satiriza su sociedad, acostumbrada a la escasez y no a la abundancia. Por tanto, el reto de alcanzar quién come más, expone las enormes carencias con las que existen en estas barriadas centroamericanas: «Entonces, la otra, o sea vos, que te decían... ¿a qué no te acordás cómo te decían? No, decime. Te vas a morir de la risa cuando te lo diga, o tal vez te arrechés $\rangle^{31}$. Así pues, esa sensación atemporal carnavalesca manifiesta durante la competencia, concluye en la vuelta a la triste realidad que circunda la vida de ambos personajes; anteriormente disfrutaron de cierto grado de libertad, mientras duró ese evento festivo que las regeneró de la normatividad instituida, aludiendo de esta manera, al ciclo constante de muerte-renovación del que apunta Mijail Bajtín en su propuesta sobre el carnaval: «Ahora, ya vez, mi hermanita, aquí nos encontramos, viendo quién nos quita el hambre... Por eso te digo Turquita: el hambre es mala consejera, no conduce a nada $)^{32}$.

Este cuento muestra que la obesidad extrema es vista de una forma cómica y burlesca en que los personajes se mofan de sus cuerpos monstruosos; además, su accionar contribuye a robustecer el imaginario negativo que predomina en las sociedades latinoamericanas sobre el tema de la obesidad. En el cuento, a los dos personajes gordos se los discrimina al no conocer sus respectivos nombres, sino que se les alude mediante apodos exclusivamente, que denigran sus derechos y sus identidades. Aunque en la trama textual los sobrenombres de Turquita y Comecuanduay son aceptados y aclamados por el colectivo, se encuentra subsumido un notorio sesgo excluyente para las personas obesas entre la comunidad.

31 Galich, 46.

32 Galich, 50. 


\section{La obesidad vista desde las relaciones maritales y su vínculo con la monstruosidad}

Con respecto al cuento «No pierda a su pareja por culpa de la grasa $\rangle^{33}$ del mexicano Carlos Velázquez, publicado en 2010, se relata la vida matrimonial de Carol y su esposo Tino. Este sujeto padece de una gordura considerable. Carol constantemente le reprocha que es un tipo descuidado con su cuerpo; incluso, lo rechaza en la intimidad debido a que está pasado de peso:

Ni creas que vamos a coger, Tino, me dijo Carol. Estás gordo otra vez. Desde que nos casamos Carol me molestaba con mi figura. ¿No se te ha ocurrido que delgado me gustarías más? Siempre que quería coger me llevaba a la báscula. Era su pretexto favorito para acostarse conmigo. No necesitaba inventarse dolores de cabeza. Que yo tuviera tetas más grandes que ella le daba asco. Mastúrbeme, le pedía. Estás pendejo, contestaba, satisfácete tú. ${ }^{34}$

Carol manipula a su conveniencia a Tino, por cuanto añora la gran fortuna de la madre de su esposo. Esta posee una cadena de zapaterías y varios edificios de apartamentos. Carol le pide a Tino que se realice una liposucción para que mejore su condición física y su vida sexual. Pero, sobre todo, Carol acude a una infinidad de insultos (mediante metáforas zoomórficas) para denigrar el físico de su esposo, el cual asume como aceptable esas palabras ofensivas en contra de su persona: «Pensé que embarazada se olvidaría de mi cuerpo de tapir. $\mathrm{Al}$ contrario. No pasaba un día sin restregarme mi gordura. Como si hiciera falta. Tapir, ornitorrinco y manatí, eran sus insultos favoritos ${ }^{35}$. Carol fortalece ese imaginario negativo, lacerante y discriminatorio que sufren periodicamente los individuos obesos, donde la sexualidad

33 Carlos Velázquez, No pierda a su pareja por culpa de la grasa (Madrid: Sexto Piso Ediciones, 2010) 13-33.

34 Velázquez, 15.

35 Velázquez, 15. 
está maniatada por un «canon estético idóneo», tanto para el hombre como para la mujer.

Aunado a ello, el discurso despectivo genera una relación de poder radical, la cual es ejercida por Carol de manera militar e imponente, y que lo muestra el narrador protagonista (Tino), mediante su focalización interna fija: «Debes hacerte la lipo, me ordenaba» ${ }^{36}$. A Carol se la asocia con una conducta monstruosa y desalmada; planea minuciosamente un robo a su suegra para saciar su consumo de cocaína, lograr que Tino se someta a la liposucción, y que ambos salgan de vacaciones a Mazatlán. Según Herra, «el monstruo es sorpresivo, crea espacios de asco, desmesura, imprevisión y desorden. Es muerte, ausencia de simetría, sinrazón, ruptura del yo ${ }^{37}$. A pesar de que Carol no es obesa, su ambición por el dinero y adicción a la cocaína impulsan a Tino a consumirla y a cometer el ansiado robo, que lo convirtierte en un monstruo, como su esposa. Pasa de ser un hijo que reconoce la gran ayuda que su madre le ha ofrecido durante su vida, a un tipo a quien solo le interesa sacarle el dinero a toda costa a su proveedora: «Y sí, habíamos robado a mamá. No una, ni dos, un chingo de veces. Para comprar cocaína ${ }^{38}$.

La relación entre Tino y Carol se convierte en un contubernio para lograr el codiciado hurto: «Ante la falta de coca y mi aumento de peso, me convenció. Yo siempre aceptaba sus chingaderas. Robaríamos a mi madre. Simularíamos un asalto. La amarraríamos con sogas y navajas. Justo a la hora en que la criada hacía el súper» ${ }^{39}$. La baja autoestima de Tino permite que Carol manipule a sus anchas para lograr el ilícito. Señala Herra que el monstruo disfraza la realidad, como en Carol: «El monstruo se infiltra en los dramas del bien y el mal. Es actor secundario, sí, pero importante, siempre enmascarado (en realidad es solo máscara) $»^{40}$. Lo que deseaba Carol era abandonar el barrio pobre

36 Velázquez, 18.

37 Herra, 3.

38 Velázquez, 19.

39 Velázquez, 26.

40 Herra, 7. 
de donde había salido; la forma de lograrlo era asegurándose de que todo el patrimonio monetario de la madre de Tino, le quedara a él como herencia. Al principio de su matrimonio, ella lo trataba bien; pero llegó a mostrar su cara monstruosa para impedir que la buena vida se le fuera de las manos, así, tuviera que asesinar a alguien para conseguirlo: «Un grito culero me hizo salir de mi trance. Carol estaba apuñalando a mi mamá. Vi su silueta de embarazada blandiendo el cuchillo con desinterés. Un desinterés que se podría traducir en torpeza. La torpeza que indicaba que Carol no sentía absolutamente nada al acuchillarla $\rangle^{41}$. La figura de la monstruosidad recae en Carol como la más ambiciosa, pero también en Tino al no oponerse a ella ante su deseo de adueñarse del caudal de su madre. Desea practicarse una liposucción para que Carol se sintiese orgullosa de que mejoró considerablemente su aspecto físico. Así, Carol avergüenza a Tino, al punto de que él se percibe como un vegetal, una berenjena, lo que le provoca gran inseguridad, el detonante para robarle a su madre.

La única persona que no discrimina a Tino es su madre adoptiva, quien lo ayuda a que termine sus estudios de Ingenería y le da ayuda económica para que salga adelante con los gastos de la casa. Sin embargo, Tino y Carol son adictos consumidores de cocaína, por lo tanto Tino lleva años robándole dinero a su madre para saciar su adicción. Carol pide que le robe otro cheque a su madre para realizarse la liposucción también; ella no se dará cuenta por ser una persona no vidente. Carol le dice a Tino que la cocaína lo hará rebajar de peso: «Carol me convenció. Siempre me convencía. La coca te quita el hambre. Con esto vas a bajar de peso, me aseguró» ${ }^{42}$. Tino está a merced de la ambición de Carol, que lo impulsa a complacerla. Ella se encarga de seguir menospreciando a Tino para que este ejecute todo lo que ella le ordena: «Eres una nutria chiquita con lupus, me recriminaba $\rangle^{43}$. A pesar del alto consumo de cocaína, Tino sigue

41 Velázquez, 29.

42 Velázquez, 19.

43 Velázquez, 19. 
engordando, aún más durante la etapa de gestación de su esposa: «La panza de Carol crecía. La mía también. En cuanto dejé de pegarle bonito al polvo, me surgió un hambre de embarazado. El estado de Carol me estaba ensanchando. La idea de ser padre me afectó tanto que me despertó un comer neurasténico» ${ }^{44}$. En ningún momento del matrimonioTino cuida su aspecto físico, lo que provoca que Carol se lo recrimine. La cocaína se convierte en su único «apoyo» moral, y que no lo juzga por ser un hombre obeso: «La coca seguía siendo mi vieja. La fiel. La que no me llamaba iguanodonte, cuerpo de tortuga de la isla Galápagos. Me reactivó al servicio» ${ }^{45}$. Como Carol no consume cocaína por su embarazo, se enoja con Tino porque él siempre llega drogado a la casa; ella le recuerda constantemente que la gordura es su peor defecto: «Saca. Saca. Saca, maldito gordo, me gritó. Pinche gordito sordero, te la ibas a meter sólo ¿verdad? Culero, pinche tapir con ADN de marrana vietnamita» ${ }^{46}$. La monstruosa influencia de Carol provoca que Tino caiga en las garras de la cocaína, con el fin de generarle dependencia al fármaco, y que esté tentado a robarle la fortuna a su madre adoptiva.

Otra circunstancia que incluía el ser obeso era que a Tino le preocupaba que su hijo naciera gordo, debido a que seguramente Carol lo iba a acosar igual que a él. Se observa que el discurso dañino y discriminatorio está radicado en el núcleo familiar y es transmitido paulatinamente a los otros ámbitos de convivencia en donde se desempeñan estas personas obesas:

Entre saque y saque yo le rezaba a San Judas Tadeo para que mi hijo no naciera defectuoso. Me daba e imploraba: Que mi hijo no salga malformado, San Juditas. Que no le falte ninguna pieza del rompecabezas. Pero mi principal preocupación era que naciera gordo. Podía adivinar su futuro: Carol lo mantendría encadenado al grupo de tragones anónimos, o lo tendría en el club de cuidakilos,

44 Velázquez, 20.

45 Velázquez, 21.

46 Velázquez, 21-22. 
a la espera de que tuviera la edad suficiente para que le realizaran una lipoescultura ${ }^{47}$.

La obesidad es una «maldición eterna» para cualquier persona, por lo que se manifiesta un repudio hacia los cuerpos obesos, sin importar la edad que se tenga, ni la condición socio-económica. Pasa el tiempo; Tino y Carol son cocainómanos, lo que le permite a Tino aprovechar un poco del placer sexual, ya que Carol le permite relaciones sin cuestionar por su obesidad: «Carol se ponía tan contenta por la droga que me permitía penetrarla. La que a cada rato nos sorprendía era la criada. Nos espiaba cuando cogíamos o cuando nos drogábamos $\rangle^{48}$. Por otra parte, el narrador se vale del discurso sardónico en relación con el tema de la obesidad cuando recurre a una analepsis narrativa para detallar el momento en que conoció a Carol: «Eso sucedió antes de que nos hiciéramos novios. Veinte o treinta kilos atrás. A Carol la conocí en la prepa. Con berrinches había conseguido sonsacarles a sus papás una colegiatura ${ }^{49}$. Durante su etapa colegial, Tino también es víctima de sus compañeros por su gordura, los cuales lo apodan «El Gordo Patineta»; no obstante, Carol no lo humilla ni lo trata mal; al proceder de un barrio pobre, está empecinada en salir a como dé lugar de su pesarosa realidad y ve en Tino la oportunidad para perpetuar un status económico holgado: «No seas mamón pinche gordo, me respondió. Al que debería hacer tamales es a ti, seguro salen hasta tres vaporeras de tu cuerpo de tapir ${ }^{50}$. Para Carol, los tamales son símbolo de la pobreza y de la deshonra, por lo que le prohíbe severamente a Tino que los consuma. Se aprovecha de que su esposo tiene ese cuerpo para marginarlo, comparándolo con un gran cerdo del cual cocinarán una gran cantidad de tamales. Carol se aprovecha de que puede manejar a Tino a su antojo y lo obliga a robarle dinero a su madre adoptiva para comprar cocaína. Al principio, Tino se arrepiente,

47 Velázquez, 22.

48 Velázquez, 22.

49 Velázquez, 23.

50 Velázquez, 25. 
pero Carol se enfada y lo humilla, hasta convencerlo de asaltar la casa de su suegra y obtener el botín:

Qué, gritó. No mames. Tú no tienes estilo. Pinche Gordo Patineta. Eres un mediocre. O qué, quieres ser toda tu vida El Gordo Patineta. Estoy harta. Eres un pobre pendejo, un maricón. Debí saberlo. Los pinches gordos son unos cobardes. No sé por qué me fijé en ti. Pinche Gordo Patineta. Gordo Patineta. Nunca vamos a dejar de ser dos limosneros que se conforman con las migajas que nos tira tu mamá. Todos los gordos son miedosos ${ }^{51}$.

Carol atrapa el interés de Tino mediante la lujuria, que le ofrecerá si está baja de peso, por lo que se conforma una lógica favorable a Tino: adelgazar $=$ sexo placentero. Esto lo engancha: $«$ Si no te rajas vamos coger más seguido. Piensa en la liposucción. Cuando seas delgado me excitaré tanto que dejaré que me la metas todos los días» ${ }^{52}$. Al final, Carol apuñala a la madre de Tino, es arrestada por la policía, y termina sus días cumpliendo una condena de veinte años en la cárcel, solo comiendo tamales. Tino se realizó la liposucción con el dinero que le robaron a su madre, y además una rinoplastia y una cirugía plástica para eliminar la papada, lo que demuestra su transformación en un monstruo ególatra e inescrupuloso como lo era también Carol. Se percibe a la sociedad mexicana, que está representada en este cuento una postura de censura completa ante este tipo de población obesa. No les importa el grado de violencia psicológica que pueda llegar a ejercer sobre un sujeto con obesidad. «Naturalizaron» este tipo de discurso implacable y deshumanizador que se le debe aplicar a los cuerpos gordos, sean femeninos o masculinos.

51 Velázquez, 27.

52 Velázquez, 28. 


\section{Conclusiones}

Existe un repudio discursivo en relación con los gordos: tales personas exhiben una gama de problemas económicos de larga data presentes en las sociedades latinoamericanas, como la desigualdad social, el latrocinio entre familiares y el paupérrimo interés por esforzarse para alcanzar sus metas personales. Lo que predomina, como en el cuento de Velázquez, es una atracción por el dinero fácil y el estilo de vida acomodado a partir del abuso de otras personas.

Conviene insistir en la necesidad de ahondar en el estudio del papel histórico que cumple el poder político dentro del cuento de Franz Galich, por cuanto se insinúa que hay intereses encontrados de dos países centroamericanos, metaforizados con la «contienda» gastronómica entre los dos personajes femeninos. Aunque no de forma directa, se manifiesta un tono denigrante ante una persona con obesidad. Desde apodos zoomórficos hasta comparaciones caricaturescas, al cuerpo obeso se le tipifica, estéticamente, en Latinoamérica, como non grato.

En el ámbito de la sexualidad, se debe profundizar en cómo se desenvuelve socialmente el individuo obeso en este campo temático en particular, sean relaciones heterosexuales como la del cuento de Velázquez, o bien buscar narraciones en que predomina la homosexualidad, para comparar ambas tendencias.

La construcción de la obesidad está plagada de sesgos difamatorios y excluyentes, producto de un ideal del cuerpo esbelto y musculoso; además, convierte a los sujetos obesos en fáciles presas del consumismo, con el ofrecimiento de cirugías estéticas y dietas milagrosas de todo tipo. En muchas ocasiones, no se garantiza el éxito de estos procedimientos, lo que implica un gasto desmedido en el individuo que busca ese ideal de cuerpo bello publicitado en los medios de comunicación masivos.

Otro aspecto por analizar es el binomio amo/esclavo y su relación odio/amor con la figura materna en la trama textual del cuento «No pierda a su pareja por culpa de la grasa». 
Por último, es necesario señalar que no existen análisis exhaustivos en relación con el consumo de drogas y los cuerpos obesos en la literatura latinoamericana contemporánea; únicamente existen aproximaciones interpretativas desde el punto de vista médico. Ello ampliaría el panorama para indagar más sobre el tema de la obesidad, ficcionalizado con frecuencia en la literatura latinoamericana. Falta mucho camino por recorrer para una comprensión amplia de los comportamientos sociales de los cuerpos obesos que se desarrollan en los corpus literarios. 